\title{
Evaluation of Carbon Aerogel Manufacturing Process in Order to Desalination of Saline and Brackish Water in Laboratory Scale
}

\author{
Mohamadreza Massoudinejad ${ }^{\mathrm{a}, \mathrm{b}}$, Yalda Hashempour ${ }^{\mathrm{a}, \mathrm{c}^{*}}$, Hamed Mohammadi ${ }^{\mathrm{a}}$ \\ ${ }^{a}$ Department of Environmental Health Engineering, School of Public Health, Shahid Beheshti University of Medical Sciences, Tehran, Iran. \\ ${ }^{b}$ Member of Safety Promotion and Injury Prevention Research Center, Shahid Beheshti University of Medical, Tehran, Iran. \\ ${ }^{c}$ Department of Environmental Health Engineering, School of Public Health, student research committee, Shahid Beheshti University of \\ Medical Sciences, Tehran, Iran. \\ Received 08 Decmber 2017; Accepted 30 January 2018
}

\begin{abstract}
Carbon aerogel its fabrication and characterization and its uses in this process were studied for desalinating of saline and brackish water. The carbon aerogel manufacturing process involves the polymerization and pyrolysis of the mixture of resorcinol and formaldehyde. Carbon aerogels were analyzed using BET, BJH, and T-plot after construction. The effect of various parameters (including the influent salt concentration, the intensity of electric current flow, the distance between the electrodes and $\mathrm{pH}$ ) on salt adsorption were studied. Analysis of BET/BJH shown that the surface of aerogel was $677.8 \mathrm{~m}^{2} / \mathrm{g}$. much of porosity in the samples of carbon aerogel were between 1-2 nm, namely micro-pour and a similar level of $456 \mathrm{~m}^{2} / \mathrm{gr}$ is dedicated to micro-pour, with a correlation coefficient (r) equal to 94.5 . According to the results, it seems that carbon aerogel electrodes have a good structure in desalination of brackish and saline water.
\end{abstract}

Keywords: Carbon Aero Gel; Desalination; Saline and Brackish Water.

\section{Introduction}

Due to the growing world population and limited water resources, desalination of water has become more important. The development of a desalination process that is more efficient and less costly than current methods is an essential requirement [1]. In $88 \%$ of the developing countries, where water scarcity affects half the world's populations and their inability to access clean drinking water, in these countries $80-90 \%$ of all diseases and $30 \%$ of all deaths are caused by a lack of proper sanitation and poor water quality [2]. Along with the increasing population, decreasing freshwater resources, increased droughts, competition for the use of common water resources, and the use of unconventional water sources, such as wastewater, brackish water, and seawater has increasingly become a global concern $[3,4]$.

Iran is among the countries that are located in the arid and semi-arid region and has a low average annual rainfall, with heterogeneous and inappropriate temporal and spatial distribution. Generally, this potential of water reflect an increased risk of drought in some parts of the country, even in normal conditions, especially in the south and southeast, has created vast problems of water supply requirements. According to available statistics, indiscriminate withdrawal of groundwater sources leading to a further decline in groundwater levels and some plains, mostly in central and eastern of Iran, are facing serious saltwater $[5,6]$. The problem evaporative processes (MSF and MED), in addition to high energy consumption, is high deposition and corrosion which is controlled only by a skilled operator [7].

* Corresponding author: yalda.hashempour@yahoo.com

\footnotetext{
doi http://dx.doi.org/10.28991/cej-030980

$>$ This is an open access article under the CC-BY license (https://creativecommons.org/licenses/by/4.0/).

(C) Authors retain all copyrights.
} 
Due to the extensive investment and operating costs on the one hand, the reverse osmosis and electrodialysis method, in addition to the limitations of these methods in the desalination of seawater, it has limited the use of this process [8].

Today, membrane technologies and ion exchange resins are the most commonly used methods for water desalination [9]. These membrane complexes produce high volumes of saline wastewater generated throughout the course of the operation; with a high sensitivity and clogging and low flexibility of the membranes against changes in water, quality and temperature are the advantages of the membrane [10]. Problems with ion exchange resins include 1) the use of hydrochloric and sulfuric acids to regenerate resins, 2) producing a large volume of saline water, 3) and the need to dispose of the wastewater into injection wells [7,9]. While the investment and operating costs are high for the existing desalination methods, and so far, the recycling technologies for seawater are at about $65 \%$ that has never been implemented [11]. While fossil fuel is the lowest in energy costs, the alternative choice would be electricity from the thermal power plants, but with the use of this type of energy in the desalination process emissions of pollutants produced such as NOx, SOx, a volatile compound, etc.

Hence, taking advantage of newest methods of desalination using the least amount of energy is necessary [11]. In many desalination units, regardless of which of these technologies are used to sweetened the water, salted water outlet issues are the main environmental issue. On the division of the U.S. Environmental Protection Agency, this concentrated material is recognized as an industrial waste product. Considering that, the concentration of the desalination effluents are approximately twice that of seawater the salt may alter the concentration in the effluent discharge locations that are dangerous for marine species. Disposal of saline effluent causes serious damage to the environment, particularly aquifers, rivers and lakes [12]. Researchers are trying to find methods that are environmentally friendly for desalination process [13]. Use of capacitive deionized technology (CDI) using carbon aerogel electrodes is one of these methods. Carbon aerogel is the most common organic material used in CDI technology and has a unique porous structure that is suitable for desalination [14].

Capacitive deionizing by use of carbon aerogel electrodes discussed as a new and innovative process in the desalination of saline and brackish waters and has many advantages compared to the other desalination processes. The low potential for clogging and fouling, easier operating conditions producing very little wastewater, aerogel electrostatic regeneration and therefore no need for acid and low energy consumption, including the benefits of this technology [15]. Integrated structure, high electrical conductivity (10-100 Siemens/cm), high surface area (400-1200 $\mathrm{m}^{2} / \mathrm{g}$ ), pore size distribution and controllable, has caused the carbon aerogel to be ideal and suitable material for the electrochemical adsorption of ions [16, 17], several studies have been conducted in this area. In a study conducted in 2002 by Gablich et al. determined that monovalent ions such as sodium, compared with polyvalent ions are absorbed quickly. In that study due to the small average size of the pores $\left(12-42 \mathrm{~m}^{2} / \mathrm{g}\right)$, the surface area of aerogels are suitable for absorbing ions, however, an average of $1 \times 10-4-2 \times 10-4$ eq of the ions was absorbed [18].

Rana et al. in a similar survey in 2004 examined the amount of chromium removal from wastewater by using carbon aerogel electrodes. In this study, removal of the chromium by the electrodes in acidic conditions $(\mathrm{pH}=2)$ and high electric load $(0.8 \mathrm{~A} \mathrm{~h})$ were reported $98.5 \%$. In another study conducted in 1996 by Farmer et al. demonstrated that the addition of the salt to remove other impurities such as heavy metals, and colloids were suspended from the water [19].

Pei et al. in 2008 studied recycling iodine saltwater produced during the extraction of gas. By the use of carbon aerogel electrodes in two cells, each containing $24 \times 16 \times 28 \mathrm{~cm}$ with an applied voltage of 1.3 volt, variable currents 60 to $70 \mathrm{Amps}, 250 \mathrm{~mL}$ per minute flow rate 50 minutes, managed to remove $69 \%$ of iodine, 8.1 percent sodium, 21.7 percent magnesium and 22 percent were calcium [15]. Given the importance of achieving technical knowledge and the development of the manufacturing technology of carbon aerogels, in this the study carbon aerogelswere built by polymerization and pyrolysis methods of formaldehyde and resorcinol mixture so that they could be used in the capacitive deionized (CPI) process for the use in the desalination of saline and brackish water. In this study, the properties of made carbon aerogels were analysed with methods BET, BJH and, T-plot and were compared with other studies

\section{Methods}

\subsection{General Method of Research}

The word aerogel consists of two words, air and gel, and contains of nanoparticles that are located in a threedimensional network with a high porosity (containing 99-95\% of the empty volume). Also, the very low density $\left(0.0011-0.5 \mathrm{~g} / \mathrm{cm}^{3}\right)$ and the high interior surface area $\left(1000-600 \mathrm{~m}^{2} / \mathrm{g}\right)$ suggest that the aerogels have unique and special characteristics such as low heat conduction, Low sound speed (Sound Insulation) and Optical Transmission. Therefore, the technical applications of this material will be developed in the future. Aerogels are also called frozen smoke, solid smoke, or blue smoke [20,21]. The aerogels and their production processes are varied according to their 
special applications. The range of application of aerogels is very extensive and includes engineering, textile, home applications, environmental engineering, energy, automotive industry, etc [21]. The aerogels include metal oxides, a combination of metal oxides, polymers, carbon, or other materials. The aerogels are made by hydrolysing soluble preforms in a sol-gel process. By adding dopants and other chemical compounds, the aerogels will be very diverse [21]. The process of making aerogels consists of two steps: 1. making a gel that the solvent has penetrated in it. 2Solvent removal by the method of special solubilisation processes. Therefore, aerogels products need to produce a gel filled with liquid components. In the second step, to remove the liquid, the gel is dried during special solubilisation processes. Drying at room temperature eliminates the gel framework, due to capillary energy in small cavities at the air-liquid level. The gel shrinks considerably and the final product contains fragments of the gel. By applying supercritical aerogel drying, a nanopore with a very low density is obtained $\left(0.05-0.1 \mathrm{~g} / \mathrm{cm}^{3}\right)$. Because of small cavities, the special surface area of this material is very high $\left(500 \mathrm{~g} / \mathrm{m}^{2}\right)[4,19]$.Preparation of carbon aerogel

In the design and construction of a desalination device for desalination of saline and brackish water using the carbon aerogel technology in a pilot scale, carbon aerogel plates should first be made. Carbon aerogel manufacturing process involves the polymerization and pyrolysis of a mixture of formaldehyde and resorcinol [10]. In such a manner that the resorcinol and formaldehyde are dissolved to a specific ratio in a specific amount of distilled water and reacts in the presence of sodium carbonate as a catalyst. Put the resulting mixture (yellow gel) at $85^{\circ} \mathrm{C} \mathrm{for} 48 \mathrm{~h}$, the polymerization process is completed but by this method, obtained aerogels must be dried by supercritical extraction that is very costly. By changing the polymerization method, the supercritical drying of aerogels can be removed and aerogels can be dried in the open air by solvents such as acetone and cyclohexane. The gel is made using the mole ratio of 1/5.5 for resorcinol and formaldehyde, respectively. The resulting gel was placed in the syringes $20 \mathrm{cc}, 24$ hours at room temperature, 24 hours at $50^{\circ} \mathrm{C}$ and 24 hours at $90^{\circ} \mathrm{C}$. The results of this process were bright red molds. That these molds are quite brittle and there was no cut. Possible cause of the non-cutting was diagnosed by oxygen entering into syringes and molar ratio used. For these reasons, in the next step, the cap test tubes were used in addition to syringes to reduce the risk of the oxygen entering the tubes. In addition, several molar ratios were used and the molar ratio of 1/3.5 was the best mixing ratio between the resorcinol and formaldehyde. Aerogels obtained from the molar ratio were cuttable in both the syringes and cap test tubes. Next, molds should be placed into the pyrolysis apparatus after cutting and drying. It is noteworthy that, after the pyrolysis process the resulting carbon aerogels carbon are black. Reducing the costs of the resulting aerogels is very high because of the high cost of the imported blades necessary for cutting these materials. As a result, the produced aerogels in the next stage was prepared in granules.

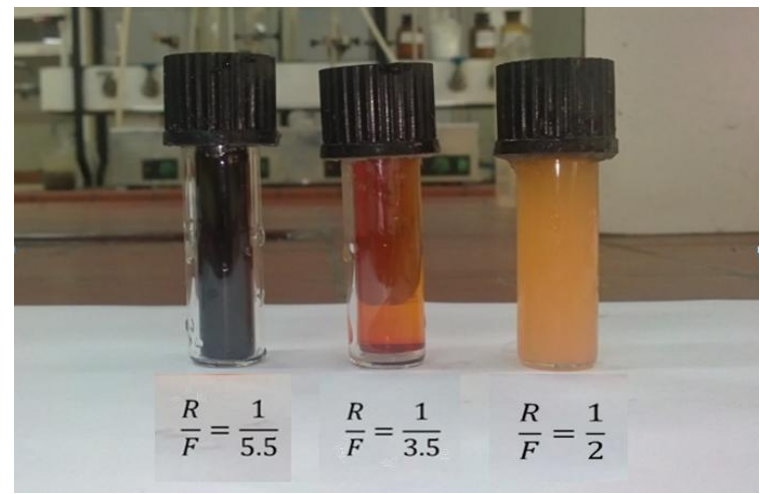

Figure 1. Aerogels after the polymerization in the different molar ratios of resorcinol and formaldehyde

For a new product again the ratio of 1/5.5, resorcinol and formaldehyde, was used. To reduce the fragility and gain more granular aerogels, stirring time of the mixture was increased. The samples were dried in the open-air method (using solutions of acetone and cyclohexane) and were placed in the tube furnace system (manufactured by Abtin, Iran) for the pyrolysis. In this way, the first flow of nitrogen was passed through the device for 30 min to remove oxygen from the pores at a temperature of zero degrees Celsius. Then, the RF aerogels were placed at $950^{\circ} \mathrm{C}$ for 4 hours. In the next step, the resulting granular carbon aerogels were entered inactivation step. For the purpose, an inert atmosphere containing argon in a tube furnace was used. The argon flow $200 \mathrm{ml} / \mathrm{min}$ for 30 min was passing through the extinguished furnace to remove the oxygen in the pores. Then, the temperature was arriving at $950^{\circ} \mathrm{C}$ at the speed of $10^{\circ} \mathrm{C} / \mathrm{min}$ and at this temperature, the activation process took place for 2.5 hours. After pyrolysis process, the obtained carbon aerogels were black.

\subsection{Structure Characterization and Measurement of Physical and Chemical Properties}

$\mathrm{pH}$ and $\mathrm{EC}$ were measured with a $\mathrm{pH}$ meter and probe. In order to measure the amount of $\mathrm{NaCl}$ inlet and outlet, $\mathrm{EC}$ was used, so that the electro-conductivity concentration calibration chart was plotted in the range of $200-3000 \mathrm{mg} / \mathrm{L}$ and was used to measure the concentrations of the inlet and the output. The electric current was measured by a 
voltmeter. All samples were analyzed in duplicate. The measurements were repeated if the results had with more than $10 \%$ variability.

The resulting granular carbon aerogels were analyzed by BET, BJH and T-plot in order to measure the specific surface area, porosity, pore volume, pore size and pore alignment pattern of the carbon aerogels synthesized.

\subsection{Design and Production of the CDI System}

Dimensions of the CDI were calculated by considering the design criteria such as the distance between electrodes, electrode size and pressure drop of device calculated. Electrodes used for the manufacture of carbon aerogel electrodes were selected from titanium. Carbon aerogel granules were glued (using silver conductive adhesive) to both sides of a sheet of titanium metal, which used as conducting electrical current as well as protection structure. To do this, a thin layer of silver adhesive was formed on titanium plates and then carbon aerogel granules were placed gently on it. The time of $15 \mathrm{~min}$ was used to complete solidification of the conductive silver adhesive at a temperature of $15^{\circ} \mathrm{C}$. Titanium plates are in direct contact with a source of energy. In general, a set of carbon aerogel plates with metal plates was placed in a chamber so-called cell. When making these cells, carbon aerogels with non-conductive plastic or glass are kept apart to prevent the establishment of a direct connection between them. In this device, the half of the carbon aerogel plates plays the role of the cathode and the other half plays the role of the Andes.

\subsection{Preparations of Samples}

Synthetic samples of saline and brackish waters were passed through the spirals form between the electrodes, the anode attracts anions, and cations are attracted to the cathode during the process. In this study, ultra-pure $\mathrm{NaCl}$ was used to produce saline water. The type of flow was batch that was driven by a continuous circular flow regime. The electrical conductivity of feed tank was measured continuously. Fixed number of electrical conductivity represented saturation of carbon aerogel electrodes. The maximum adsorption capacity of carbon aerogel was determined with a mass balance of salt adsorbed to the aerogel used in the cells. After applying a voltage between two adjacent carbon aerogel electrodes, cations and anions are drawn to the cathode and anode, respectively.

\subsection{Measured Parameters to Evaluating the Performance of Carbon Aerogel}

Electrical currents used in this study were $0.5,1$ and $1.5 \mathrm{~A}$, concentrations used were 500, 1,000 and 1,500 mg/L, the intervals used $0.5,1$ and $1.5 \mathrm{~cm}$, flow rate used were 50, 100 and $150 \mathrm{ml} / \mathrm{min}, \mathrm{pH}$ used were 5.7, 7 and 9. During the experiment of desalination using carbon aerogel electrodes, data from voltage, electrical current and electrical conductivity (EC) of solution were recorded during testing to evaluate the CDI process. By applying different flow rate, $\mathrm{pH}$, and changing the distance between the electrodes, the influence of these parameters on the performance of the system in different concentrations of saline and brackish waters were examined. In practice, the regeneration of a carbon aerogel was done with a reverse flow or flow interruption for 30-15 minutes and the cycle was repeated. In addition, an electrical transducer (Zhaokin, rxn 202D) that was made in China was used to generate the electricity.

The digital pH meter WTW that was made in Germany was used to measure the $\mathrm{pH}$ of the system. To measurement of Input and output level of the $\mathrm{NaCl}$ conductivity meter was used, thus the calibration curve of concentrationconductivity in the range of concentrations $200-3000 \mathrm{mg} / \mathrm{L}$ plotted and it was used to measure the inlet and outlet concentrations.

\section{Results and Discussion}

\subsection{Carbon Aerogel Characterization}

BET, BJH, and T-plot methods were used in order to surface analysis and measuring the diameter of the porous of carbon aerogel. The results of surface analysis by BJH/BET represented the level equivalent was $677.8 \mathrm{~m}^{2} / \mathrm{gr}$. As can be seen in Figures 2 and 3, the surface analysis in nitrogen adsorption-desorption method, BJH, also shows that a large portion of the porosity of the carbon aerogel samples, namely micro-pour and was between 1-2 nm. The results of surface analysis by T-plot showed that the specific surface of micro-pour were $456 \mathrm{~m}^{2} / \mathrm{gr}$, with a correlation coefficient (r) is equal 94.5. The results of the surface analyze with this study was comparable by the study of Ying et al (2002), so the Ying et al. study, $85 \%$ of the surface area of the carbon aerogel composed of micro-pout porosity [17].

\subsection{Evaluating the Performance of Carbon Aerogel}

The removal efficiency at a constant condition in electrical current of $1.4 \mathrm{~A}$, electrodes distance of $0.5 \mathrm{~cm}$ and the flow rate of $50 \mathrm{ml} / \mathrm{min}$ at different concentrations of $500,1,000$ and $1,500 \mathrm{mg} / \mathrm{L}$ was $1.18 \times 10-4,1.3 \times 10-4$ and $1.43 \times 10-4 \mathrm{~mole} \mathrm{NaCl} / \mathrm{gr}$ of carbon aerogels, respectively. Statistical analysis showed a relationship between concentration and absorption of salt per gr of the aerogels $(\mathrm{p} \leq 0.01)$. In addition, the optimal experimental conditions are shown in Table 1. The cause of the low overall efficiency in this study was a low number of carbon aerogel electrodes compared to the tested concentration and volume of brine. Meanwhile, the salt absorption by carbon aerogel electrodes in this study was comparable to the research that has been done in this field. 


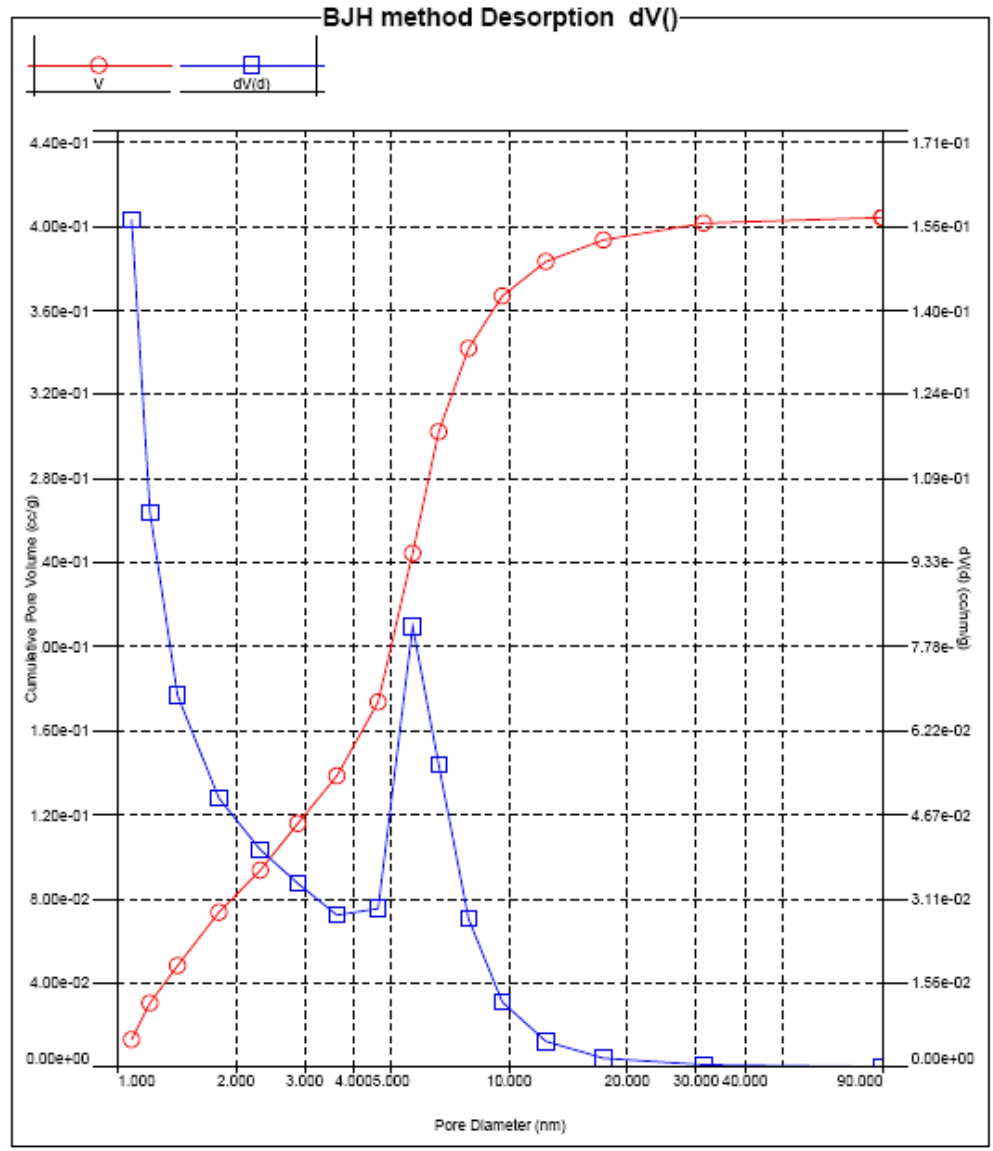

Figure 2. Surface analysis of nitrogen desorption using BJH method
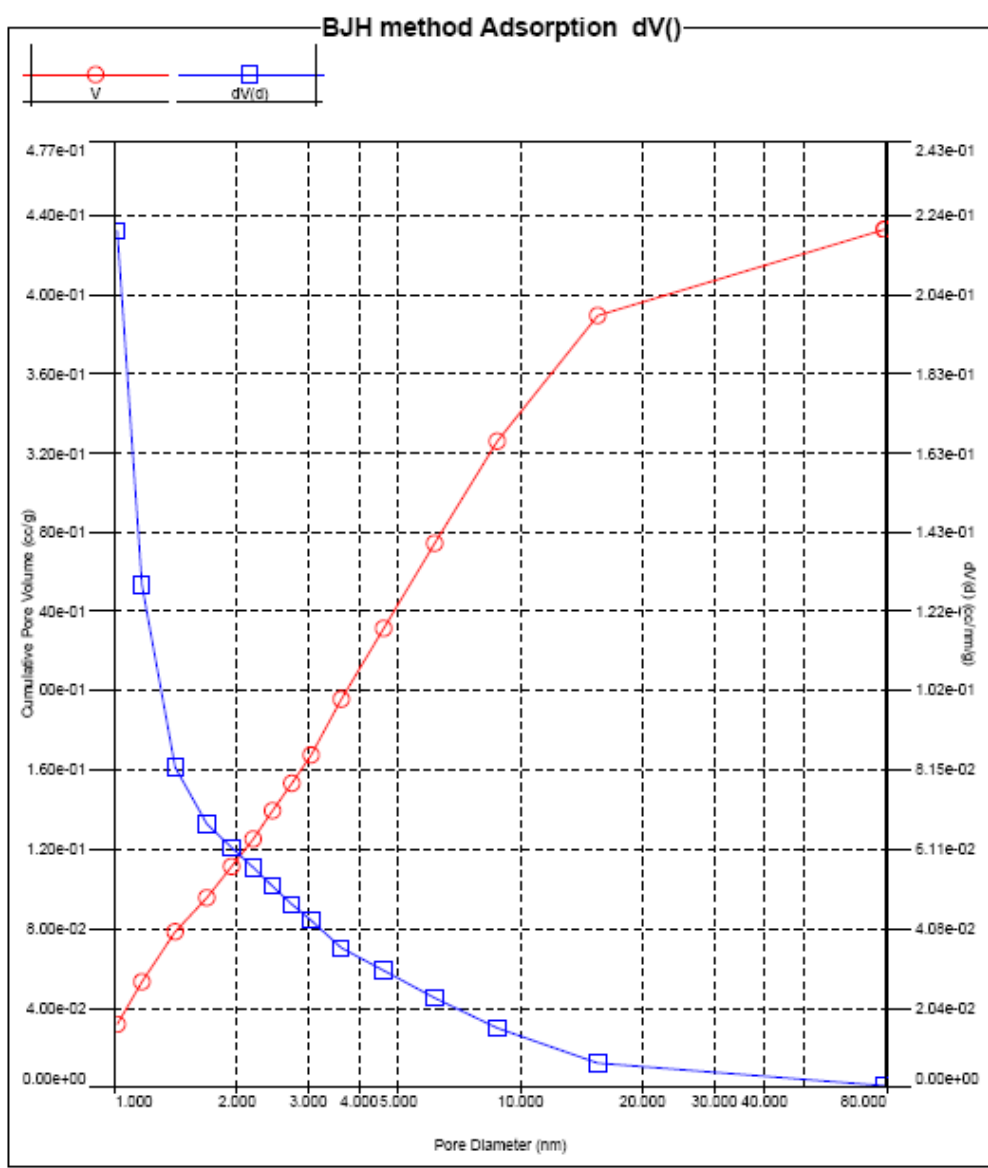

Figure 3. Surface analysis of nitrogen adsorption using BJH method 
According to the results in Table 2, the absorption rate in this study have adopted by research of Jung at al. In their study, the absorption of a single cell capacitive deionized was $1.2 \times 10-4 \mathrm{Mol} \mathrm{NaCl} / \mathrm{gr}$ aerogel and its value for multicellular was $2.1 \times 10-4 \mathrm{Mol} \mathrm{NaCl} / \mathrm{gr}$ aerogel [22]. In the study of $\mathrm{Xu}$ et al. that showed the absorption rate of $7 \mathrm{mg}$ $\mathrm{NaCl} / \mathrm{gr}$ of carbon aerogel that, confirm this claim [15]. In this research, the plates of cutting organic aerogel have been used to make of carbon aerogels. While in this study, to the making of the carbon aerogel electrodes, it was used granular type as that had a specific surface area equal to $677.8 \mathrm{~m} / \mathrm{g}$ and that was equivalent to those derived from the study of Jung et al. $(610 \mathrm{~m} / \mathrm{g})$. Besides, absorption capacity was equivalent to and competitive with the rest of the investigations. The number of electrodes used in this study was 12 and dimensions of $4 \times 13 \mathrm{~cm}$ were selected. Using the $67.8 \mathrm{gr}$ of granular carbon aerogel, $1248 \mathrm{~cm} 2$ of surface area was created.

In the study in 2008 [15] with the aim of recycling iodine from salt water that was conducted using two cells. Each cell containing 24 carbon aerogel electrode with dimensions of $16 \times 28 \mathrm{~cm}$, voltage $1.3 \mathrm{v}$, electrical currents ranged from 60 to $70 \mathrm{~A}$, the flow rate of $250 \mathrm{~mL} / \mathrm{min}$ for $50 \mathrm{~min}$ and using $650 \mathrm{~g}$ of carbon aerogel they were able to remove $69 \% \mathrm{I}, 8.1 \% \mathrm{Na}, 21.7 \% \mathrm{Mg}$ and $22 \% \mathrm{Ca}$ [15]. Thus, increasing the number of carbon aerogel electrodes, and subsequently an increase in mass of carbon aerogel, overall efficiency of the device can be upgraded.

In the study of Farmer et al. in 1995, the overall level of carbon aerogel electrodes was $18000 \mathrm{~cm}^{2}$, which were comparable with other desalination processes with extremely low energy consuming.

In this study, to remove salts of carbonate, sulfate and sodium phosphate from samples containing $100 \mathrm{ppm}, 192$ pairs electrodes with an interval of $0.5 \mathrm{~cm}$ were used and were able successfully to remove $65 \%$ of the ion with the voltage of $1.2 \mathrm{~V}$ and flow rates of $1 \mathrm{~L} / \mathrm{min}$. In these studies, by increasing the input concentration, the absorption rate of carbon aerogel electrodes were increased, as well [23].

In contrast to these studies, considering the distance between the electrodes used in this research was selected from the same samples (due to technical problems in making the pilot), and to compensate for this increased distance, high voltages, and high electrical currents were used.

Table 1. The highest efficiencies obtained from Capacitor deionized system using carbon aerogel electrodes

\begin{tabular}{cccccc}
\hline $\begin{array}{c}\text { Concentration, } \\
\mathbf{m g ~ N a C l} / \mathbf{L}\end{array}$ & $\begin{array}{c}\text { Electrodes distance, } \\
\mathbf{c m}\end{array}$ & $\begin{array}{c}\text { Flow rate, } \\
\mathbf{m L} / \mathbf{m i n}\end{array}$ & $\begin{array}{c}\text { Electrical current, } \\
\mathbf{A}\end{array}$ & $\mathbf{p H}$ & $\begin{array}{c}\text { Efficiency, } \\
\mathbf{\%}\end{array}$ \\
\hline 500 & 0.5 & 50 & 1.5 & 5.7 & 26.85 \\
500 & 0.5 & 100 & 1.5 & 5.7 & 25 \\
500 & 1 & 50 & 1.5 & 5.7 & 25 \\
500 & 0.5 & 50 & 1 & 5.7 & 24.07 \\
\hline
\end{tabular}

If the distance between the electrodes is reduced, absorption efficiency increases due to making the potential difference between the electrodes and the formation of an electric double layer.

In Farmer et al., a study on the distance between the electrodes was $0.5 \mathrm{~mm}$. This distance in Pei et al. study for desalination of brackish water was $2.3 \mathrm{~mm}$. In the study of Tung et al, investigated the removal of ions from aqueous solutions, the distance was considered $6 \mathrm{~mm}$ while in the present study the optimum distance of $5 \mathrm{~mm}$ was obtained. One possible reason for the low efficiency of the device could be attributed to the distance between the electrodes. Because the cations and anions fall into a trap in the electrical double layers and are released in the stage of recycling by reversing the flow for 15 to 45 minutes. Subsequently, the salt concentrations are increased by creating an electric current and passing time and gradually increases during regeneration [12, 23]. 
Table 2. Comparison of various studies in the field of desalination using CDI technique based on carbon aerogel

\begin{tabular}{|c|c|c|c|c|c|}
\hline No. & Aerogels characteristics & Aim of the study & Investigated parameters & Results & Reference \\
\hline 1 & $\begin{array}{l}\text { Cuttable Organic aerogels, Density: } \\
0.45 \mathrm{~g} / \mathrm{cm}^{3} \text {; } \\
\text { Porosity: } 80 \% \text {; } \\
\text { Specific surface: } 610 \mathrm{~m}^{2} / \mathrm{g} \\
\text { Specific capacity: } 220 \mathrm{~F} / \mathrm{g}\end{array}$ & $\begin{array}{l}\text { Desalination of } \\
\text { synthetic water }\end{array}$ & $\begin{array}{l}\text { Voltage: } 1-1.5 \mathrm{~V} ; \\
\text { Concentration: } 12.5-1000 \\
\mathrm{mgNaCl} / \mathrm{L} ; \\
\text { Flow rate: } 100-400 \\
\mathrm{~mL} / \mathrm{min}\end{array}$ & $\begin{array}{l}\text {-Absorption rates for a single-celled } \\
\text { and multicellular capacitive deionized } \\
\text { were } 1.2 \times 10^{-4} \text { and } 2.1 \times 10^{-4} \mathrm{Mol} \\
\mathrm{NaCl} / \mathrm{gr} \text { Aero gel, respectively. } \\
\text { - Removal of a CDI system with } 6 \text {-cell } \\
\text { units equal } 92.8 \% \text { and } 97.6 \% \text { for the } \\
\text { electrical current } 1.5 \text { and } 1.7 \mathrm{~V} \text {, } \\
\text { respectively. } \\
\text {-Optimized conditions: Voltage: } 1.7 \mathrm{~V} \text {; } \\
\text { concentration } 50 \mathrm{mg} \mathrm{NaCl} / \mathrm{L} \text {; flow rate: } \\
400 \mathrm{~mL} / \mathrm{min} \text {. }\end{array}$ & {$[22]$} \\
\hline 2 & $\begin{array}{l}\text { Density: } 0.78 \mathrm{~g} / \mathrm{cm}^{3} ; \\
\text { Specific surface area: } 113 \mathrm{~m}^{2} / \mathrm{g} ; \\
\text { Specific capacity: } 2 \mathrm{~F} / \mathrm{g} ; \\
\text { Average particle size: } 4.28 \mathrm{~nm} \\
\text { Two cells, each cell containing } 24 \\
\text { carbon aerogel electrodes. }\end{array}$ & $\begin{array}{l}\text { Recycling of iodine } \\
\text { from salt water }\end{array}$ & $\begin{array}{l}\text { Voltage: } 1.3 \mathrm{~V} \text {; } \\
\text { Flow rate: } 700-3000 \\
\text { mL/min; } \\
\text { Concentration: } 50-5000 \\
\mathrm{mg} / \mathrm{L} \text {; } \\
\text { Variable electrical current } \\
\text { of } 60 \text { to } 70 \mathrm{~A} .\end{array}$ & $\begin{array}{l}\text {-Maximum absorption capacity of } \\
\text { resins: } 7 \mathrm{mg} \mathrm{NaCl} / \mathrm{g} \text { carbon aerogel } \\
\text {-Removal } 69 \% \text { of iodine, } 8.1 \% \mathrm{Na} \text {, } \\
21.7 \% \mathrm{Mg} \text { and } 22 \% \mathrm{Ca} \text {. }\end{array}$ & {$[15]$} \\
\hline 3 & $\begin{array}{l}192 \text { pairs electrodes with distances } \\
\text { of } 0.05 \mathrm{~cm} \text {. }\end{array}$ & $\begin{array}{l}\text { Removal of carbonate, } \\
\text { sulfate and sodium } \\
\text { phosphate from samples } \\
\text { containing } 100 \mathrm{ppm} \text { of } \\
\text { these compounds }\end{array}$ & $\begin{array}{l}\text { Voltage: } 1.2 \mathrm{~V} \\
\text { Flow rate: } 1 \mathrm{~L} / \mathrm{min}\end{array}$ & $\begin{array}{l}\text {-Removal of } 65 \% \text { of the ions } \\
\text {-Increasing of input concentrations lead } \\
\text { to increase absorption rate of carbon } \\
\text { aerogel electrodes. }\end{array}$ & [23] \\
\hline
\end{tabular}

Environmental $\mathrm{pH}$ creates a severe effect of many chemical reactions. Therefore, this study examined its effects. With decreasing $\mathrm{pH}$, the amount of absorption is increased so that at $\mathrm{pH} 5.7$ the best results were obtained. Statistical analysis also showed a significant relationship between $\mathrm{NaCl}$ concentration and removal efficiency at $\mathrm{p} \leq 0.01$. In this study, distilled water had pH 5.7 and to increase the pH values of 7 and 9 , the $\mathrm{NaOH}$ solution was used. With the addition of $\mathrm{NaOH}$ to the sample, the amount of sodium ions was increased, which in turn increases the EC in the sample. Therefore, in the higher $\mathrm{pH}$, the $\mathrm{EC}$ of new solution was regarded as input EC to investigate the absorption of $\mathrm{NaCl}$ on carbon aerogel electrodes.

With reducing flow rate, the efficiency of absorption was increased. Statistical analysis showed a significant correlation between the rate of $\mathrm{NaCl}$ concentration and removal efficiency at $\mathrm{p} \leq 0.01$. The best results were obtained in the flow rate of $50 \mathrm{ml} / \mathrm{min}$ and this suggests that the lower flow rate the electrodes have a greater opportunity to attract the ions. The study conducted by Xu et al., in which an increase in flow rate of 700 to $3000 \mathrm{ml} / \mathrm{min}$ the absorption rate was reduced from 3.2 to $2.5 \mathrm{mg}$ TDS/gr carbon aerogel [15]. However, a study conducted by Jung et al. removal efficiency increased with increasing flow rate [22]. In this study, the cause of increased efficiency in higher flow rate was attributed to increasing of Reynolds numbers. Since the electrical adsorption is a reversible process, ions are released fast with the cutout the electrical current or reverse flow. Therefore, the electrodes can be regenerated and reused repeatedly.

Desalination takes place during charging of electrodes, while regeneration occurs during electrical discharge with switching cathode and anode electrodes.

Concentration and electrical conductivity of the samples decrease during charging and increases during the regeneration phase. Using reverse-flow to regenerate the electrode instead cutout the electrical current is necessary for the maintenance of electrical adsorption capacity and extend the life of the electrodes. Economically, the viability and sustainability of the CDI process depend on the carbon aerogel electrodes lifetime. Another advantage of using reverse flow in regenerating of aerogel is extending the lifetime of them in addition to their high efficiency. Thus, if the cutout of the electrical current is used to regenerating of the electrodes, 6-8\% of the carbon aerogel capacity is destroyed in voltage of 1.27 with the passing of time [24].

If regenerating of electrodes is done with the cutout of electrical current, EC shortly is increased in their use the due to release ions that have fallen into the trap of carbon aerogels in the previous experiments. Nevertheless, if the reverse process takes place for regenerating the electrodes, the increase in EC will not happen at the beginning of the experiment and absorption will be done in less time [25].

\section{Conclusion}

Specifications of capacitive deionized System (CDI) using carbon aerogel electrodes as a cost-effective desalination technique was studied. The main findings of this study were as follows: 
- RF carbon aerogel manufacturing process involves the polymerization and pyrolysis of resorcinol and formaldehyde. Analysis of the surface area by BJH/BET represented the surface area equivalent $677.8 \mathrm{~m}^{2} / \mathrm{gr}$. Much of the carbon aerogel porosity in the samples was micro-pour between 1-2 nm, which allocated $456 \mathrm{~m}^{2} / \mathrm{gr}$.

- In this study, optimized conditions for the CDI system include electrical current 0 f $1.5 \mathrm{~A}$, the distance between electrodes $0.5 \mathrm{~cm}, \mathrm{pH} 5.7$ and flow rate $50 \mathrm{ml} / \mathrm{min}$. The removal efficiency of the system in optimal conditions with 12 electrodes containing 6.8 gr of granular carbon aerogel was equal to $26.85 \%$.

- In general, the survey results indicate that this process is capable of removing salt from saline and brackish water. Since Capacitive deionized Technology (CDI) as compared to the membrane complex, is relatively new, there is no long-term operating data available for the industrial scale. In addition, due to the lack of this information, the prediction for the lifetime of the electrodes also on the clogging effects because the chemical and biological agents are difficult. If the technology of capacitive deionized (CDI) is operated on an industrial scale, it can be used as an alternative to other conventional processes, such as ion exchange resins to desalination of saline and brackish water. Hence, the production of large volumes of secondary waste can be prevented and thus chemical regeneration of resins should be avoided. The energy efficiency of this technology has led to CDI competing with other desalination processes. However, larger studies are necessary for the field of carbon aerogels manufacturing.

\section{Acknowledgement}

Authors hereby appreciate the efforts of the Research Council, School of Public Health, and Shahid Beheshti University of Medical Sciences, which provided the necessary facilities to conduct this research.

\section{References}

[1] W.H.O. "Desalination for safe water supply: guidance for the health and environmental aspects applicable to desalination" Geneva, Switzerland: Public Health and the Environment World Health Organization (2007).

[2] J.E. Miller. "Review of water resources and desalination technologies" Sandia national labs unlimited release report SAND2003-0800 (2003).

[3] Y. Junjie, S. Shufeng, W. Jinhua, L. Jiping. "Improvement of a multi-stage flash seawater desalination system for cogeneration power plants" Desalination 217 (2007): 191-202. 10.1016/j.desal.2007.02.016.

[4] J. Yu, J. Qin, K.A. Kekre, B. Viswanath, G. Tao, H. Seah. "Impact of operating conditions on performance of capacitive deionisation for reverse osmosis brine recovery" Journal of Water Reuse and Desalination 4 (2014): 59-64. 10.2166/wrd.2013.008.

[5] K.L. Benko, J.E. Drewes. "Produced water in the Western United States: geographical distribution, occurrence, and composition" Environmental Engineering Science 25 (2008): 239-246. 10.1089/ees.2007.0026.

[6] W. Wang, M. Esparra, H. Liu, Y. Xie. "Application of forward osmosis in reusing the brackish concentrate produced in reverse osmosis plants with secondary treated wastewater as feed solution: a case study" Journal of Water Reuse and Desalination (2016): 533-543. 10.2166/wrd.2016.097.

[7] K. Kadirvelu, J. Goel, C. Rajagopal. "Sorption of lead, mercury and cadmium ions in multi-component system using carbon aerogel as adsorbent" Journal of Hazardous Materials 153 (2008): 502-507. 10.1016/j.jhazmat.2007.08.082.

[8] M. Ramezanianpour, M. Sivakumar. "Energy evaluation and treatment efficiency of vacuum membrane distillation for brackish water desalination" Journal of Water Reuse and Desalination 5 (2015): 119-131. 10.2166/wrd.2014.025.

[9] U.S.DOE. A guide to practical management of produced water from onshore oil and gas operations in the United States Washington, DC: 2006.

[10] K.-L. Yang, T.-Y. Ying, S. Yiacoumi, C. Tsouris, E.S. Vittoratos. "Electrosorption of ions from aqueous solutions by carbon aerogel: an electrical double-layer model" Langmuir 17 (2001): 1961-1969. 10.1021/la001527s.

[11] R. Broséus, J. Cigana, B. Barbeau, C. Daines-Martinez, H. Suty. "Removal of total dissolved solids, nitrates and ammonium ions from drinking water using charge-barrier capacitive deionisation" Desalination 249 (2009): 217-223. 10.1016/j.desal.2008.12.048.

[12] Y. Al-Wazzan, M. Safar, S. Ebrahim, N. Burney, A. Mesri. "Desalting of subsurface water using spiral-wound reverse osmosis (RO) system: technical and economic assessment" Desalination 143 (2002): 21-28. 10.1016/S0011-9164(02)00217-5.

[13] L. Zou, G. Morris, D. Qi. "Using activated carbon electrode in electrosorptive deionisation of brackish water" Desalination 225 (2008): 329-340. 10.1016/j.desal.2007.07.014.

[14] R. Pekala, J. Farmer, C. Alviso, T. Tran, S. Mayer, J. Miller, et al. "Carbon aerogels for electrochemical applications" Journal of non-crystalline solids 225 (1998): 74-80. 10.1016/S0022-3093(98)00011-8. 
[15] P. Xu, J.E. Drewes, D. Heil, G. Wang. "Treatment of brackish produced water using carbon aerogel-based capacitive deionization technology" Water Research 42 (2008): 2605-2617. 10.1016/j.watres.2008.01.011.

[16] J. Farmer, D. Fix, G. Mack, R. Pekala, J. Poco. "Capacitive deionization of NH4ClO4 solutions with carbon aerogel electrodes" Journal of applied electrochemistry 26 (1996): 1007-1018. 10.1007/BF00242195.

[17] T.-Y. Ying, K.-L. Yang, S. Yiacoumi, C. Tsouris. "Electrosorption of ions from aqueous solutions by nanostructured carbon aerogel" Journal of colloid and interface science 250 (2002): 18-27. 10.1006/jcis.2002.8314.

[18] C.J. Gabelich, T.D. Tran, I.M. Suffet. "Electrosorption of inorganic salts from aqueous solution using carbon aerogels" Environmental science \& technology 36 (2002): 3010-3019. 10.1021/es0112745.

[19] J. Farmer, D. Fix, R. Pekala, J. Nielsen, A. Volpe. The Use of Carbon Aerogel Electrodes for Environmental Cleanup. DTIC Document, 1996.

[20] J. Ma, L. Wang, F. Yu. "Water-enhanced performance in capacitive deionization for desalination based on graphene gel as electrode material" Electrochimica Acta (2018).

[21] X. Quan, Z. Fu, L. Yuan, M. Zhong, R. Mi, X. Yang, et al. "Capacitive deionization of NaCl solutions with ambient pressure dried carbon aerogel microsphere electrodes" RSC Advances 7 (2017): 35875-35882.

[22] H.-H. Jung, S.-W. Hwang, S.-H. Hyun, K.-H. Lee, G.-T. Kim. "Capacitive deionization characteristics of nanostructured carbon aerogel electrodes synthesized via ambient drying" Desalination 216 (2007): 377-385. 10.1016/j.desal.2006.11.023.

[23] J.C. Farmer, D.V. Fix, G.V. Mack, R.W. Pekala, J.F. Poco, editors. Capacitive deionization with carbon aerogel electrodes: carbonate, sulfate, and phosphate. International SAMPE Technical Conference; 1995: SAMPE SOCIETY FOR THE ADVANCEMENT OF MATERIAL.

[24] M.E.I. Tchobanoglous. "Wastewater engineering: treatment, disposal, re-use" McGraw-Hill Book Company. New York, 2 nd Edition,(07 A MET) (1979): 938.

[25] J.C. Farmer, D.V. Fix, G.V. Mack, R.W. Pekala, J.F. Poco. "Capacitive deionization of NaCl and NaNO3 solutions with carbon aerogel electrodes" Journal of the Electrochemical Society 143 (1996): 159-169. 10.1149/1.1836402. 